\title{
10 Lead Standard
}

National Cancer Institute

\section{Source}

National Cancer Institute. 10 Lead Standard. NCI Thesaurus. Code C90349.

An electrocardiogram lead placement on the patient using a ten electrode lead set to synthesize standard 12 lead electrocardiog raph data to elicit an electrical view of the heart. 